\title{
Quality Analysis of Roughing Reamers That Use WNMG080408-P30 Mechanical Fixed Cutting Inserts
}

\author{
Valentin DIŢU \\ Transilvania University of Brașov, Romania, vditu@unitbv.ro
}

\begin{abstract}
Due to the many advantages, the using of mechanical fixed cutting inserts extents to development of different cutting tools, like the reamers. Roughing reamers with switchable inserts that use WNMG mechanical fixed inserts are used for both enlarging and reaming. Knowing the value of the electrical current at cutting is important because it provides much information regarding the quality appreciation of the tool, which is determined by the tool life of the used cutting inserts. In this paper there are experimentally determined values of the electrical current at cutting at processing 1C45 steel with roughing reamers in the range of diameters of $20 \div 153 \mathrm{~mm}$ that use at cutting edge mechanical fixed WNGB080408-P30 cutting inserts.
\end{abstract}

\section{Keywords}

cutting, enlarging, electrical current at cutting

\section{Introduction}

The cutting process still remains the main method for processing metals due to the diversity of the obtained parts and also to the obtained precision. There were developed new processing systems and new types of cutting tools that completes the processing systems. Using robust tools that allow obtaining a high precision became a necessity. Another necessity it becomes the using of a large diversity of cutting tools that allow obtaining complex surfaces. The manufacturing companies of cutting tools (ex. [5]) extend the use of mechanical fixed cutting inserts to the construction of tool systems. There are no exceptions to the roughing reamers which are frequently used cutting tools. In the bibliographic source [5] are presented roughing reamers on range of diameters (ex. $20 \div 24,23 \div 27$, $26 \div 33, \ldots, 130 \div 153$ ). According to [5], in Figures 1 and 2 (where: 1 - cutting insert type WNGB; 2 channels for cutting fluid) it is presented the design and the image of a roughing reamer that uses WNMG080408-P30 mechanical fixed cutting inserts, used at processing 1C45 steel.

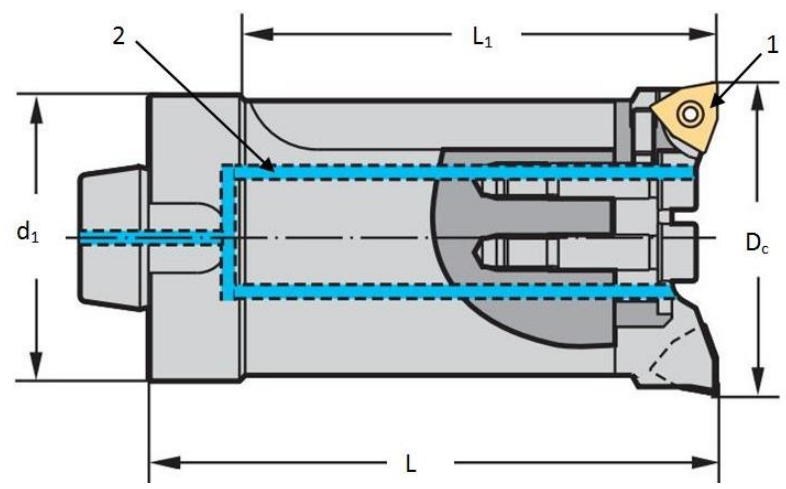

Fig. 1. The design of a roughing reamer with mechanical fixed cutting inserts [5]

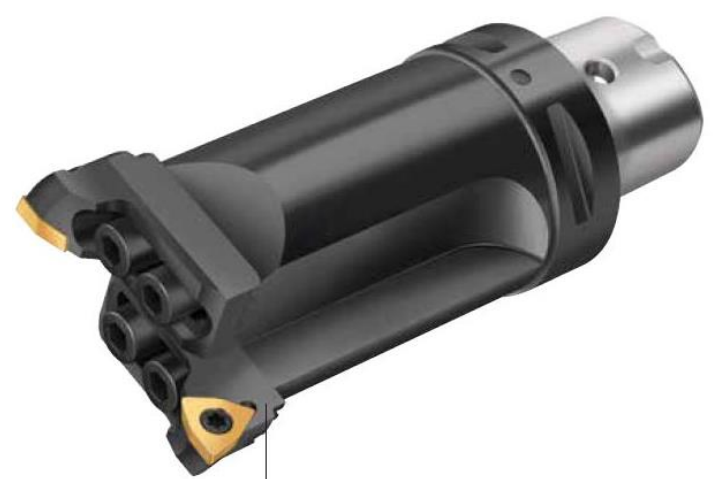

Fig. 2. The image of a roughing reamer with mechanical fixed cutting inserts [5]

The roughing reamer has two cutting edges, the possibility of adjusting the diameter and inner cooling to the cutting edge. It can be used for regular holes but also for deep holes and the mechanical fixed inserts can be of different types acquisitioned from different manufacturers, between them being the WNMG080408-P30 type. 


\section{Experimental Data}

The quality appreciation of a cutting tool and the wear state of the cutting edge can be done knowing the electrical current resulted from the cutting process (e.g. [1...4]). To estimate the value of the electrical current at cutting, because the roughing reamer is more expensive than a cutting tool support used for turning and the enlargement with mechanical fixed inserts can be assimilated with turning using two cutting tools diametrically opposed, the estimation strategy involves the next steps:

- Acquisition of six cutting inserts type WNMG080408-P30 and a cutting tool support;

- Measuring electrical current at turning 1C45 steel;

- Quality appreciation of cutting tools;

- Estimation of electrical current at cutting at processing with roughing reamer;

- Quality estimation of the roughing reamer.

There were acquisitioned six cutting inserts from producer " $\mathrm{X}$ ". The cutting inserts are titanium coated with a $2 \mu \mathrm{m}$ layer and it was used a MWLNR $2020 \mathrm{~K} 08 \mathrm{~N}$ type support.

The experiments were done on 1C45 material which has the following chemical composition: $\mathrm{C}=0.45 \%, \mathrm{Si}=0.22 \%, \mathrm{Mn}=0.56 \%, \mathrm{P}=0.025 \%, \mathrm{~S}=0.034$. The tensile strength of $1 \mathrm{C} 45$ steel is 660 $\operatorname{MPa}\left(660 \mathrm{~N} / \mathrm{mm}^{2}\right)$ and the hardness is $224 \mathrm{HB}$.

The measurement of the electrical current at cutting was done with the experimental stand presented in Figure 3.
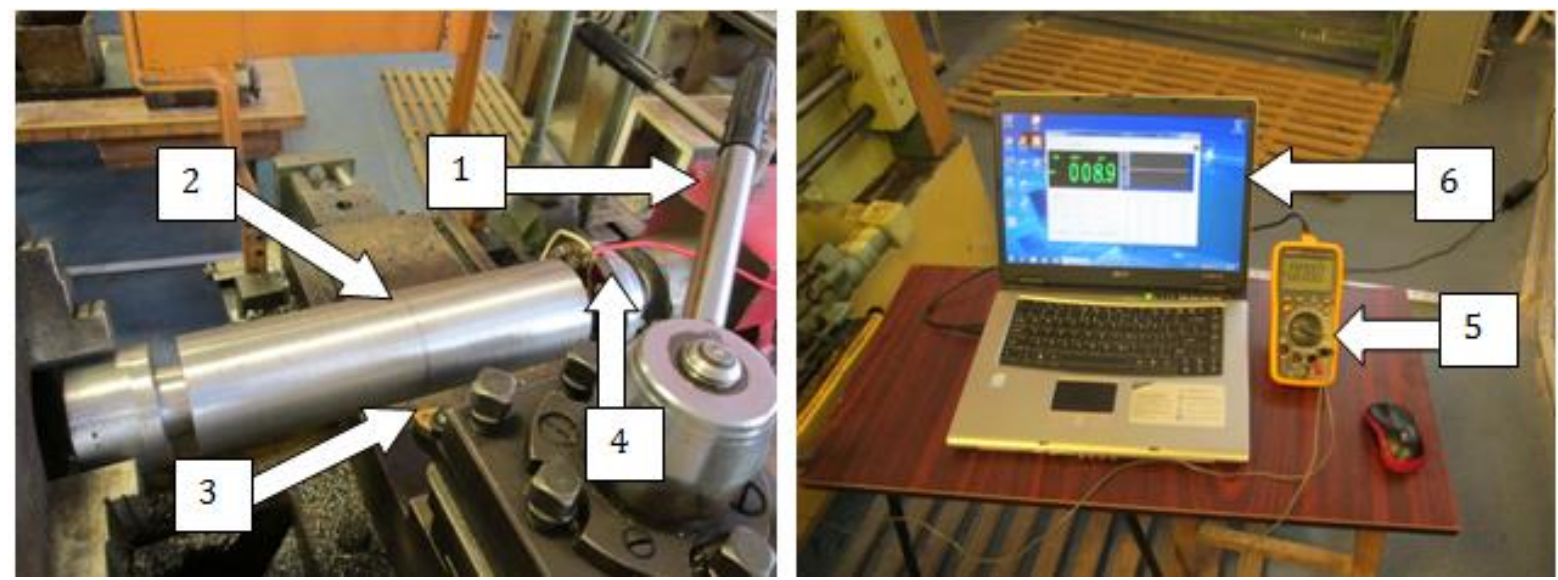

Fig. 3. Experimental stand used in measuring process of the electrical current at turning

1 - an universal lathe; 2 - part; 3 - cutting tool; 4 - electrical current collector; 5 - a digital multi-meter with a data acquisition function; 6 - a PC

The multi-meter has a software that allows data acquisition from second to second and exports the measured values in an Excel file.

The experimental results are presented in Table 1.

Analyzing data from Table 1, but also Figures 4 and 5, it can be seen that the cutting inserts from producer " $X$ " present different quality. Inserts 2, 3 and 4 present similar quality because the values of the average electrical current voltage are similar. Inserts 1, 5 and 6 present different quality than inserts 2, 3 and 4 . So, the cutting insert 1 is better than inserts 2, 3 and 4 because the average voltage of the electrical current is lower. As the value of the voltage of the electric cutting current is directly proportional to the temperature in the cutting zone it results that the first insert will cut better and will have a longer tool life. In the specialty literature it is estimated the variation of tool life. Inserts 5 and 6 present a lower quality than inserts 2,3 and 4 because the average value of the electrical current voltage is higher and also the temperature in the cutting zone is higher resulting a shorter tool life of the cutting edge.

If in the roughing reamer there are fixed the inserts 1 and 6 the cutting tool will be unbalanced from tool life point of view. Insert 6 will get first to the admissible wear and the insert 1 can cut with almost 23\% longer (according to [2]). As the inserts are being changed at the same time it result a loss of $23 \%$ from the cost of an insert. 
RECENT, Vol. 149, no. 3(56), December, 2018

Table 1. Experimental values for the electrical current at cutting

\begin{tabular}{|c|c|c|c|}
\hline $\begin{array}{l}\text { No. of insert and cutting } \\
\text { parameters }\end{array}$ & No. of edge & $\begin{array}{c}\text { Voltage "U" of } \\
\text { electrical current at } \\
\text { cutting }[\mathrm{mV}]\end{array}$ & $\begin{array}{l}\text { Average values of the } \\
\text { electrical current at } \\
\text { cutting voltage [mV] }\end{array}$ \\
\hline \multirow{3}{*}{\begin{tabular}{l}
\multicolumn{1}{c}{$\mathbf{1}$} \\
Cutting speed: $107 \mathrm{~m} / \mathrm{min}$ \\
Feed: $0.208 \mathrm{~mm} / \mathrm{rev}$ \\
Cutting depth: $1.5 \mathrm{~mm}$
\end{tabular}} & 1.1 & 7.9 & \multirow{3}{*}{8.77} \\
\hline & 1.2 & 8.7 & \\
\hline & 1.3 & 9.7 & \\
\hline \multirow{3}{*}{$\begin{array}{l}\mathbf{2} \\
\text { Cutting speed: } 107 \mathrm{~m} / \mathrm{min} \\
\text { Feed: } 0.208 \mathrm{~mm} / \mathrm{rev} \\
\text { Cutting depth: } 1.5 \mathrm{~mm}\end{array}$} & 2.1 & 10.1 & \multirow{3}{*}{10.93} \\
\hline & 2.2 & 11.0 & \\
\hline & 2.3 & 11.7 & \\
\hline \multirow{3}{*}{\begin{tabular}{l}
\multicolumn{1}{c}{3} \\
Cutting speed: $107 \mathrm{~m} / \mathrm{min}$ \\
Feed: $0.208 \mathrm{~mm} / \mathrm{rev}$ \\
Cutting depth: $1.5 \mathrm{~mm}$
\end{tabular}} & 3.1 & 10.1 & \multirow{3}{*}{11.07} \\
\hline & 3.2 & 11.1 & \\
\hline & 3.3 & 12.0 & \\
\hline \multirow{3}{*}{$\begin{array}{l}\mathbf{4} \\
\text { Cutting speed: } 107 \mathrm{~m} / \mathrm{min} \\
\text { Feed: } 0.208 \mathrm{~mm} / \mathrm{rev} \\
\text { Cutting depth: } 1.5 \mathrm{~mm}\end{array}$} & 4.1 & 10.3 & \multirow{3}{*}{11.33} \\
\hline & 4.2 & 11.4 & \\
\hline & 4.3 & 12.3 & \\
\hline \multirow{3}{*}{$\begin{array}{l}\mathbf{5} \\
\text { Cutting speed: } 107 \mathrm{~m} / \mathrm{min} \\
\text { Feed: } 0.208 \mathrm{~mm} / \mathrm{rev} \\
\text { Cutting depth: } 1.5 \mathrm{~mm}\end{array}$} & 5.1 & 11.6 & \multirow{3}{*}{12.17} \\
\hline & 5.2 & 12.3 & \\
\hline & 5.3 & 12.6 & \\
\hline \multirow{3}{*}{\begin{tabular}{l}
\multicolumn{1}{c}{$\mathbf{6}$} \\
Cutting speed: $107 \mathrm{~m} / \mathrm{min}$ \\
Feed: $0.208 \mathrm{~mm} / \mathrm{rev}$ \\
Cutting depth: $1.5 \mathrm{~mm}$
\end{tabular}} & 6.1 & 12.3 & \multirow{3}{*}{12.60} \\
\hline & 6.2 & 12.6 & \\
\hline & 6.3 & 12.9 & \\
\hline
\end{tabular}

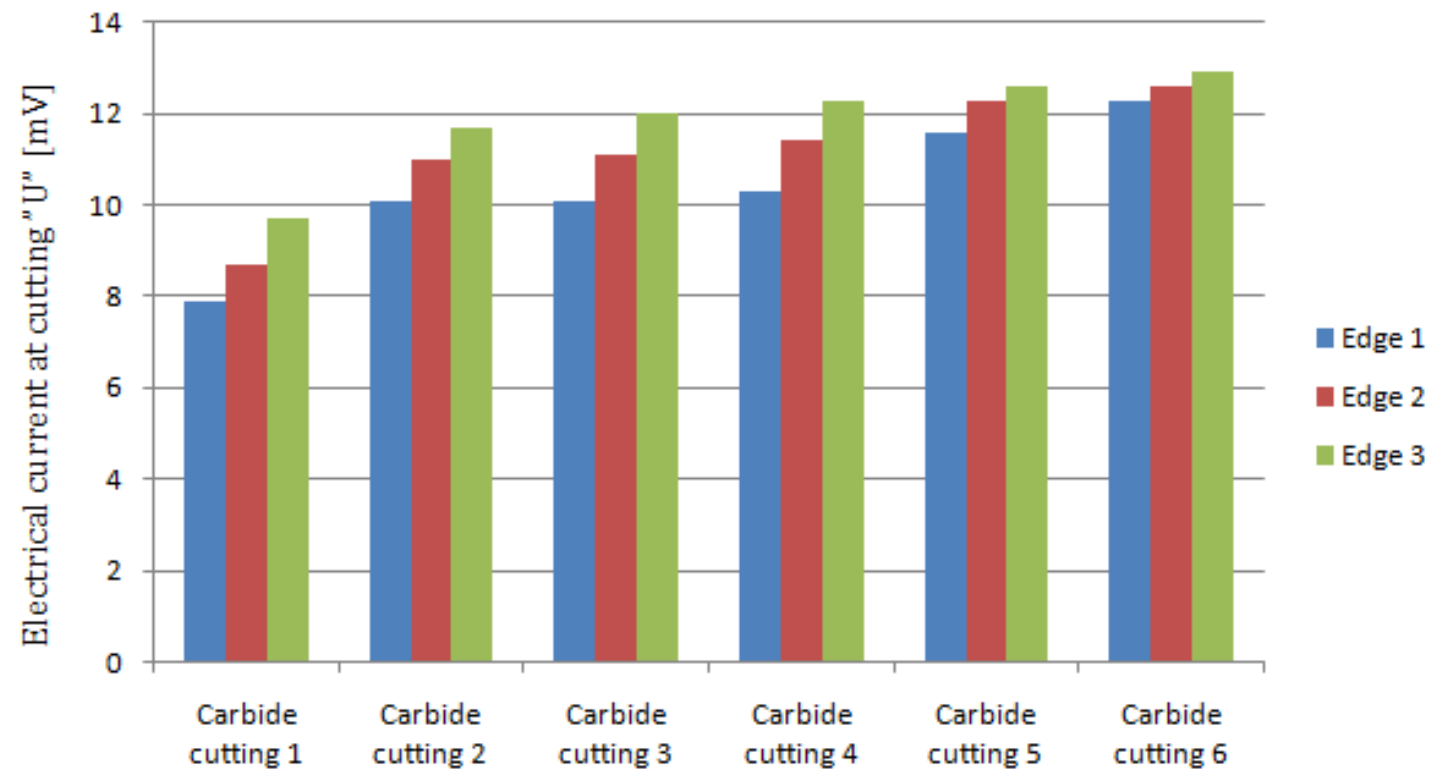

Fig. 4. Graphical representation of the data presented in Table 1

The roughing reamer that has the inserts 3 and 4 is balanced from tool life point of view.

When comparing the values of the electrical current at cutting from Table 1 with the values obtained in the bibliographic source [4] where there were used for experimental tries triangular inserts with chip breaker type TNMG 160408-P30 but uncoated with titanium it can be seen that they 
are similar. The conclusion is that the $2 \mu \mathrm{m}$ layer on the WNMG080408-P30 inserts is not thick enough to improve the cutting performances of the insert.

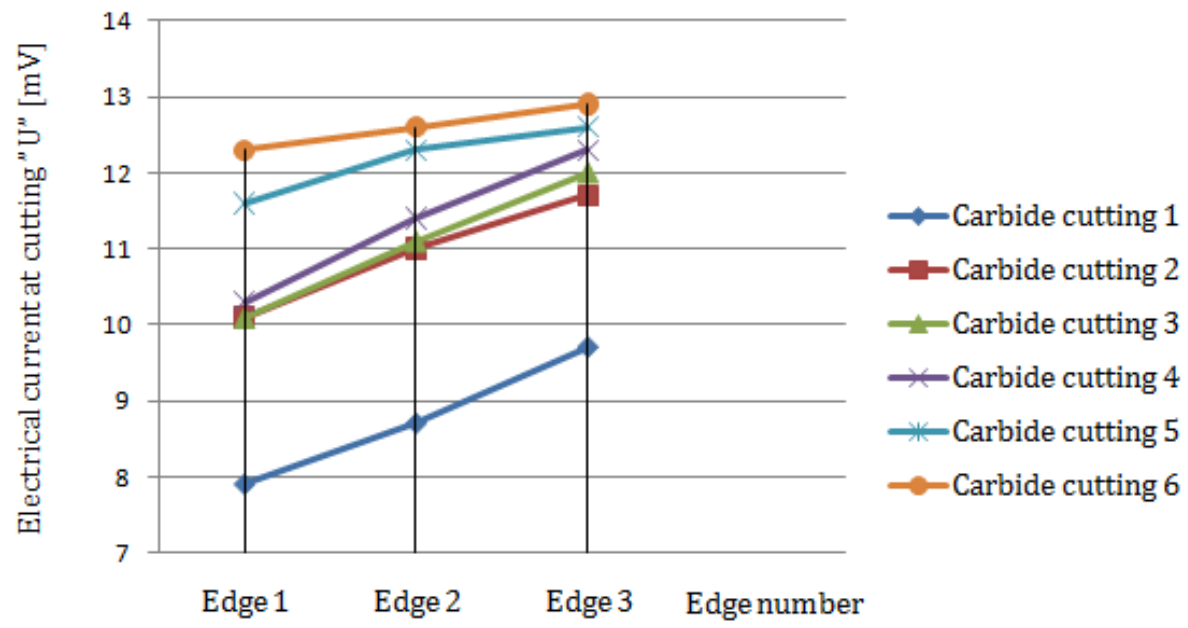

Fig. 5. Graphical representation of the electrical current voltage on three edges on the cutting insert

\section{Conclusions}

From the experimental tries, the next conclusions can be drawn:

- the quality of a roughing reamer with 2 edges (presented in Figures 1 and 2) depends on the quality of the used cutting inserts;

- to obtain a balanced roughing reamer from tool life point of view the quality of the two cutting inserts must be similar;

- to select similar quality inserts the measurement of the electrical current at cutting is a safe and simple method;

- when comparing the voltage of the electrical current of the inserts with the voltage of the electrical current for inserts TNMG 160408-P30 (bibliographic source [4]) it can be seen that the $2 \mu \mathrm{m}$ titanium coating of the WNMG080408-P30 insert is not enough to improve the performances.

\section{References}

1. Daicu R., Diţu V. (2016): Innovative analysis of HS 6-5-2 drills edges quality. The 4th International Conference on Computing and Solutions in Manufacturing Engineering 2016 - CoSME'16, MATEC Web Conf., Vol. 94, eISSN: 2261-236X, https://doi.org/10.1051/matecconf/20179402004

2. Medison V.V. (2014): Influence of the thermoelectric current on the tool-life in cutting titanium alloys. Russian Engineering Research, ISSN 1068-798X, Vol. 34, No. 4, p. 234-238, DOI: 10.3103/S1068798X14040133, https://www.researchgate.net/publication/271629580 Influence of thermoelectric current on the tool lif e in cutting titanium alloys

3. Diţu V., Lepădătescu B. (2013): The Utilization of Electrical Cutting Signal for the Quality Control of the Mettalic Carbide Plates, of the Edge of the Drill, and for the Appreciation in the Cutting Zone. Recent Advances in Circuits, Systems and Automatic Control (Proc. of the 12 th WSEAS Int. Conference CSECS '13), ISBN: 978-960474-349-0, p. 282-286, http://www.wseas.us/e-library/conferences/2013/Budapest/CSECS/CSECS-40.pdf

4. Diţu, V. (2011): Comparative study of the cutting thermocurrent at OLC45 steel turning with TNMG 160408-P30 and TNUN 160412-P30 plates mechanically fixed. Recent Researches in Manufacturing Engineering, (Proccedings of 3rd WSEAS MEQAPS 2011), ISBN 978-960-474-294-3, p. 80-83, http://www.wseas.us/elibrary/conferences/2011/Brasov2/MEQAPS/MEQAPS-15.pdf

5. Daicu R., Oancea Gh. (2015): Electrical Current at Metal Cutting Process: A Literature Review. Applied Mechanics and Materials, ISSN 1662-7482, Vol. 808, p. 40-47, https://doi.org/10.4028/www.scientific.net/ AMM.808.40

6. https://www.walter-tools.com/SiteCollectionDocuments/downloads/global/catalogues/en-gb/general-catalogue2016-en.pdf 